\title{
DESENVOLVIMENTO DO PRODUTO SOUND GLOVE: UMA LUVA SONORA
}

\section{SOUND GLOVE PRODUCT DEVELOPMENT: A SONOROUS GLOVE}

\author{
Ana Paula Claudino dos Santos ${ }^{1}$, Graduanda. \\ Jucelia Salete Giacomini da Silva², Dra. \\ (1) Instituto Federal de Santa Catarina (IFSC) \\ e-mail: anapclaudino@gmail.com \\ (2) Instituto Federal de Santa Catarina (IFSC) \\ e-mail: jucelia.giacomini@ifsc.edu.br
}

Palavras-chave: Luva Sonora, Ergonomia, Design de Produto.

Este artigo trata do desenvolvimento da Sound Glove, luva sonora que possibilita emitir sons com base em dispositivos eletrônicos apenas usando movimentos das articulações das mãos. O projeto foi realizado em colaboração com alunos da área de Música, Engenharia Eletrônica e Design de Produto. Na área de Design o projeto fundamentou-se no estudo ergonômico, visando o melhoramento do produto para que a mesma possa atender a diversos usuários.

Key-words: Sound Glove, Ergonomics, Product Design.

This article deals with the Sound Glove development. The sound glove is a product that makes it possible to emit sounds based on electronic devices, using movements of the hands joints only. The project was carried out in collaboration with students from the Music, Electronic Engineering and Product Design Areas. In the Design Area the project was based on the ergonomic study, aiming the product improvement to attend several user's needs.

\section{Introdução}

Este produto foi desenvolvido dentro do projeto MUDEI na Porto Design Factory, uma empresa de plataforma experimental em Porto, Portugal e consiste em uma luva sensorial denominada Sound Glove, que possui componentes eletrônicos que foram elaborados e aperfeiçoados ao longo do processo, assim como a parte estética e formal do produto. $\mathrm{O}$ intercâmbio foi realizado no período de setembro de 2016 a janeiro de 2017 e foi proporcionado pelo programa PROPICIE, EDITAL $N^{\circ}$ 01/2016 PROPPI, com a parceria estabelecida pelo Instituto Federal de Santa 


\section{$16^{\circ}$ \\ ERGODESIGN USIHC CINAHPA}

Catarina (IFSC) com o Instituto Politécnico do Porto (IPP).

A luva sensorial tem como objetivo reproduzir diferentes sons, apenas usando movimentos das articulações das mãos, podendo usá-las em diferentes situações, tais como: espetáculos, concertos ou mesmo para diversão, podendo futuramente ser aprimorada para utilização em outras áreas. Durante o desenvolvimento deste projeto não foi definido um objetivo específico para a utilização da luva sonora, pois o foco é voltado para o funcionamento por meio dos movimentos das mãos, deixando em aberto o uso da mesma para quaisquer aplicações.

O propósito inicial é a reprodução de sons por meio de movimentos dos dedos com base nos sensores eletrônicos de pressão, flexão e movimento giroscópio que foram desenvolvidos e aprimorados por alunos da área de Engenharia Eletrônica. Os sensores funcionam a partir de movimentos, estes sensores foram distribuídos na parte superior da mão, nas articulações dos dedos, nos dedos indicador e médio e sensores de pressão nas pontas dos dedos e na palma da mão.Sob a ótica do Design, o projeto da luva tem como objetivo, além do desenvolvimento estético-formal, o melhoramento ergonômico, pois como trata-se de uma luva, o ideal é que a mesma possa atender a diversos usuários.

O estudo ergonômico abordado neste artigo trás o processo de entendimento da mão humana, com intuito de compreender o uso da luva por possíveis usuários e identificar os principais desconfortos durante o uso.

Além disso, foram estudados materiais para a confecção da luva, pois a seleção de um material adequado, flexível e resistente é imprescindível para o bom funcionamento do produto. Também foram criados e aperfeiçoados dispositivos eletrônicos para que a luva possa ser funcional, ou seja, produzir sons usando o movimento das mãos. Por fim, uma alternativa foi selecionada e prototipada, para assim poder ser produzida.

\section{Procedimentos metodológicos}

O método escolhido para o desenvolvimento do projeto foi o de Löbach (2001). De acordo com Löbach (2001, p. 139), a criatividade do designer é manifestada quando ele une conhecimentos e experiências e é capaz de associar informações a determinado problema, a fim de estabelecer novas relações entre eles. Deste modo, para definir alguns aspectos específicos do projeto, foi realizada uma sessão de brainstorming com os orientadores do projeto e os alunos de graduação. Neste processo cada pessoa contribuiu com ideias, soluções e assim foram sendo delimitados os requisitos para dar início ao processo de desenvolvimento da luva. Löbach (2001) defende que um bom produto de design deve atender as três funções básicas, sendo elas: prática, estética e simbólica. Ainda aponta que o processo de design não é só um processo criativo como também consiste no desenvolvimento da solução de um problema.

Segundo Löbach (2001), a função prática tem relação com a capacidade do produto em atender a uma necessidade de uso, podendo ser avaliada segundo a sua usabilidade, um produto deve ser usado por usuários específicos para alcançar objetivos específicos com efetividade, eficiência e satisfação em um contexto. Já sua função estética, seria promover a capacidade de sensibilizar pelo menos um dos sentidos humanos, assim, os produtos necessitam ser projetados com elementos estéticos (cores, formas, texturas, sons, entre outros). A função simbólica consiste no inter-relacionamento do produto com as representações mentais já relacionadas ao objeto, neste caso a luva seria a representação de um objeto já existente, mas que apresente outros modos de uso. A luva sonora exerce a sua função que vai além da função usual de uma luva, que é vestir e proteger o usuário para temperaturas baixas ou para proteção laboral. Ela tem sua função prática e estética, que se correlaciona com um instrumento musical, mas que pode ser vestido. Os elementos estéticos são associações com 


\section{$16^{\circ}$ \\ ERGODESIGN USIHC CINAHPA}

conceitos e emoções que não são fruto da pura experiência do usuário com o produto.

Löbach (2001) propõe que o processo de design siga as seguintes etapas: há um problema a ser definido; são agrupadas informações sobre este problema a serem analisadas e relacionadas entre si de forma criativa; alternativas para solucionar o problema são criadas e julgadas de acordo com critérios preestabelecidos e, por fim a melhor alternativa é desenvolvida. Faz parte do trabalho do designer propor solução ao problema, em forma de produto industrial, agrupando características que satisfaçam as necessidades humanas (LÖBACH, 2001; p.141). As etapas do método são apresentadas na Figura 01 a seguir:

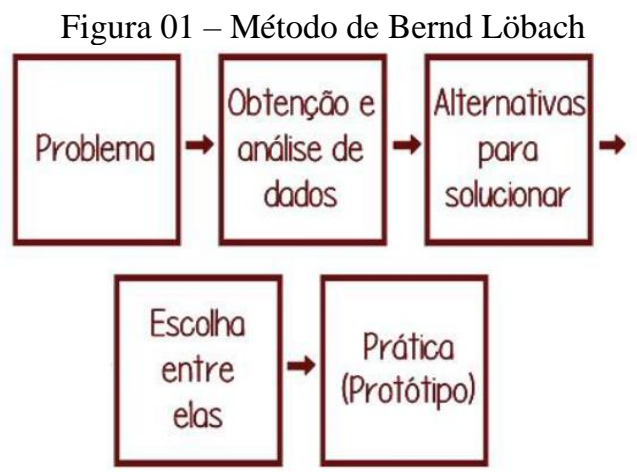

Fonte: Baseado em Löbach (2001)

Na primeira etapa do método foi estabelecido o problema, que seria a identificação e definição de uma necessidade e oportunidade de projeto onde foram levantadas as questões dos componentes eletrônicos que a luva necessitava e como poderiam ser melhorados. Seguindo para a obtenção e análise de dados foi efetuada a fundamentação teórica, a análise de similares e um estudo sobre a antropometria da mão.

Após essas etapas foram elaborados os requisitos do produto e foram geradas as alternativas e conceitos. Na sequência foi desenvolvida a matriz de seleção e foram realizados alguns testes com o produto visando definir a melhor alternativa final para ser prototipada e produzida Deste modo, o método $16^{\circ}$ Ergodesign - Congresso Internacional de Ergonomia e Usabilidade de Interfaces Humano Tecnológica: Produto, Informações Ambientes Construídos e Transporte

$16^{\circ}$ USIHC - Congresso Internacional de Ergonomia e Usabilidade de Interfaces Humano Computador

CINAHPA | 2017 - Congresso Internacional de Ambientes Hipermídia para Aprendizagem. proposto por Löbach (2001) foi aplicado ao presente projeto, seguindo as etapas propostas e visando encontrar soluções criativas e inovadoras para a solução do problema.

\section{Antropometria da mão}

O estudo sobre a antropometria da mão teve como finalidade analisar as variáveis antropométricas dos indivíduos, entendendo as dimensões de diferentes gêneros da mão humana, sendo possível projetar produtos adequados para distintos usuários. Para isso, foi realizado um estudo da antropometria da mão, sendo necessário para aplicar no projeto da luva de modo que fosse possível sua utilização por diversos usuários, adequando-se para diversos tamanhos, dimensões e espessuras. Segundo Iida (2005), os dados antropométricos podem variar de acordo com os aspectos físicos individuais (biótipos, gênero, idade) e populacionais (origem, etnia, época), além de outras variáveis como posições de trabalho, limites de alcance, dispositivos de interface tecnológica, entre outras.

Figura 02 - Antropometria da mão

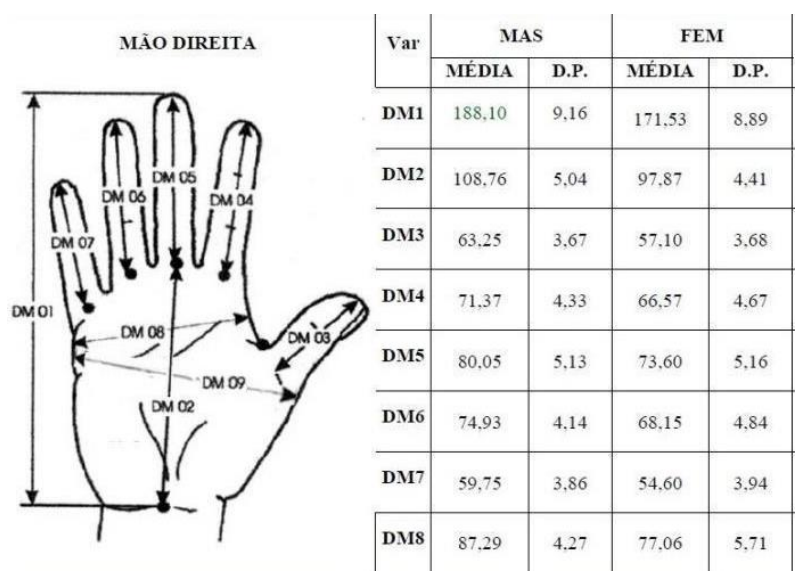

Fonte: Paschoarelli et al (2010)

A Figura 02 acima mostra as dimensões das mãos masculina e feminina, podendo-se notar a diferença de tamanhos. Para o desenvolvimento da Sound Glove é necessário entender os 


\section{$16^{\circ}$ \\ ERGODESIGN USIHC CINAHPA}

dimensionamentos da mão humana, assim como os materiais da luva que são essenciais para o desenvolvimento da luva.

\section{O projeto da luva Sound Glove}

Este projeto de uma luva sonora tem como requisito principal agregar sensores eletrônicos distribuídos, sendo possível produzir diversos sons, usando apenas o movimento das mãos, pressão e flexão das articulações dos dedos. Os componentes eletrônicos assim como os aspectos estético-formais da luva, foram desenvolvidos por estudantes das áreas de Eletrônica, Design e Música.

A luva captura os movimentos das mãos e um software permite que essas informações sejam mapeadas passando mensagens de controle musicais que podem ser facilmente encaminhadas para o software. São dispostos alguns sensores localizados no interior da luva. Ou seja, sensores de pressão, sensores de flexão, um sensor de movimento que são dispostos na parte de cima da mão, nas articulações, no dedo indicador e médio e sensores de pressão nas pontas dos dedos e na palma da mão.

O maior desafio da luva além de desenvolver os sensores, foi acoplá-los no produto e ainda desenvolver características estético-formais diferenciadas, buscando um material resistente e flexível ao mesmo tempo, para que possa ser usado por distintos usuários. O protótipo da luva (vide Figura 03) foi produzido simplificadamente para que fosse possível realizar testes e melhorar a manipulação e compreensão de uso da mesma. $16^{\circ}$ Ergodesign - Congresso Internacional de Ergonomia e Usabilidade de Interfaces Humano Tecnológica: Produto, Informações Ambientes Construídos e Transporte

$16^{\circ}$ USIHC - Congresso Internacional de Ergonomia e Usabilidade de Interfaces Humano Computador

CINAHPA | 2017 - Congresso Internacional de Ambientes Hipermídia para Aprendizagem.
Figura 03 - Protótipo inicial da luva Sound Glove

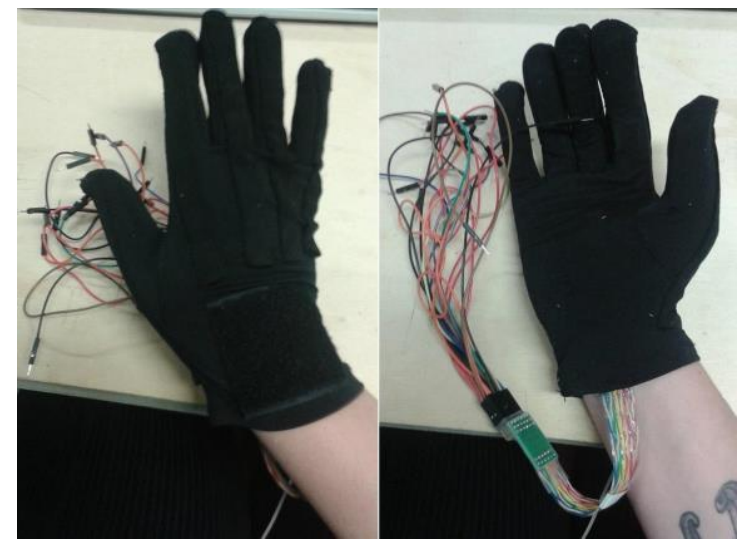

Fonte: Autoria própria

O protótipo foi produzido com a intenção de verificar questões sobre os componentes eletrônicos, como os sensores encaixavam-se na luva, além disso, também foi possível perceber que a luva possuía material excessivo, o que dificultava na flexibilidade da mão.

\subsection{Definição dos requisitos do produto}

A partir de algumas limitações elencadas no brainstorming, foram sendo delimitados novos requisitos, propiciando assim uma maior limitação às alternativas que foram desenvolvidas. Os requisitos foram definidos ao longo das reuniões em grupo pelos orientadores e alunos e também a partir das necessidades observadas no uso do produto. A luva será usada por diversos usuários e deste modo necessita possuir dimensões adequadas às diferentes formas das mãos e permitir o acoplamento dos componentes eletrônicos. Sendo assim, precisa ser adaptável à diferentes

características e tamanhos de mãos, possuindo ainda material flexível e/ou ajustável. Deste modo, definiu-se que o produto deveria
Realização:

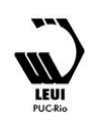




\section{$16^{\circ}$ \\ ERGODESIGN USIHC CINAHPA}

apresentar uma diferenciação estética e formal, ou seja, possuindo um design inovador, buscando novos padrões dos desenhos da luva, mas preocupando-se também com os componentes eletrônicos que serão acoplados ao produto.

\subsection{Alternativas desenvolvidas e matriz de seleção}

Com base nas pesquisas realizadas foram desenvolvidas diferentes alternativas para a luva. Após essa etapa efetuou-se uma matriz de seleção dos modelos propostos e verificou-se segundo os requisitos, qual solução apresenta maior adequabilidade para o desenvolvimento do produto final.

Figura 04 - Matriz de seleção $16^{\circ}$ Ergodesign - Congresso Internacional de Ergonomia e Usabilidade de Interfaces Humano Tecnológica: Produto, Informações Ambientes Construídos e Transporte

$16^{\circ}$ USIHC - Congresso Internacional de Ergonomia e Usabilidade de Interfaces Humano Computador

CINAHPA | 2017 - Congresso Internacional de Ambientes Hipermídia para Aprendizagem.

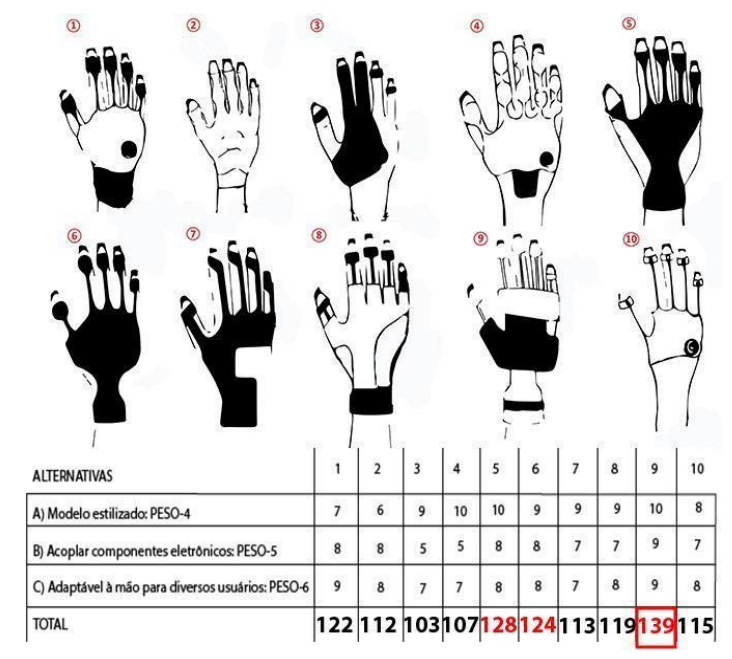

Fonte: Autoria própria

Na matriz de seleção, três alternativas foram avaliadas com um resultado de nota maior, são as alternativas cinco, seis e nove, sendo que a maior nota entre as três alternativas finais foi a de número nove. Por isso, a alternativa nove foi redesenhada tendo em vista a realização de algumas melhorias. Foi dado peso quatro (4) para o requisito A) Modelo estilizado, peso cinco (5) para o requisito B) Acoplar componentes eletrônicos e peso seis e peso seis (6) para o requisito C) Adaptável à mão para diversos usuários,C) Adaptável à mão para diversos usuários, assim, multiplicando cada peso com a sua nota e por fim somando os resultados $\mathrm{A}, \mathrm{B}$ e $\mathrm{C}$ visando obter o resultado final.

\subsection{Definição dos Materiais}

Nas primeiras etapas do projeto, durante o brainstorming, foi sugerido alguns materiais para serem utilizados na Sound Glove, pensando na sua flexibilidade e ao mesmo tempo resistência. Os materiais sugeridos foram o neoprene e a utilização dos têxteis.

O neoprene é um material altamente resistente, composto por borracha de policloropeno 


\section{$16^{\circ}$ \\ ERGODESIGN USIHC CINAHPA}

dublado com tecido de helanca nas duas faces. Além de ser o melhor material para a confecção de alguns produtos e útil, pois é um isolante térmico. O neoprene também é muito resistente e ao mesmo tempo elástico, o que é o ideal para a luva. Por se tratar de um tecido emborrachado, ele acaba sendo um material higiênico, visto que esses produtos podem ser facilmente higienizados.

O tecido têxtil é um material à base de fios de fibra natural e também podendo ser sintético geralmente utilizado na fabricação de roupas. A malha também pode otimizar o fluxo de ar e propiciar maior mobilidade e flexibilidade da mão, o que é importante já que um dos requisitos definidos pela equipe. O elastano Spandex é um material capaz de recuperar o comprimento original mesmo após alongamento e retração. Também é um material leve com uma boa resistência, o que pode ser ideal nesse caso, já que distintos usuários podem utilizar.

Figura 05 - Material luva $16^{\circ}$ Ergodesign - Congresso Internacional de Ergonomia e Usabilidade de Interfaces Humano Tecnológica: Produto, Informações Ambientes Construídos e Transporte

$16^{\circ}$ USIHC - Congresso Internacional de Ergonomia e Usabilidade de Interfaces Humano Computador

CINAHPA | 2017 - Congresso Internacional de Ambientes Hipermídia para Aprendizagem.

\subsection{Material do fecho}

O material escolhido para o fecho da luva foi o velcro, por ser um sistema simples e bastante eficaz. O velcro possui um sistema de fixadores e fechos feitos a partir de duas partes independentes de tecidos que unem-se, encaixando facilmente. Outro ponto positivo do velcro é que também é possível fazer regulagem do tamanho que for necessário. Sendo assim, diversos usuários podem usar a luva, pois o velcro permite esse sistema de regulagem. (ZARIFEH, 2012).

Figura 06 - Material fecho 


\section{$16^{\circ}$ \\ ERGODESIGN USIHC CINAHPA}

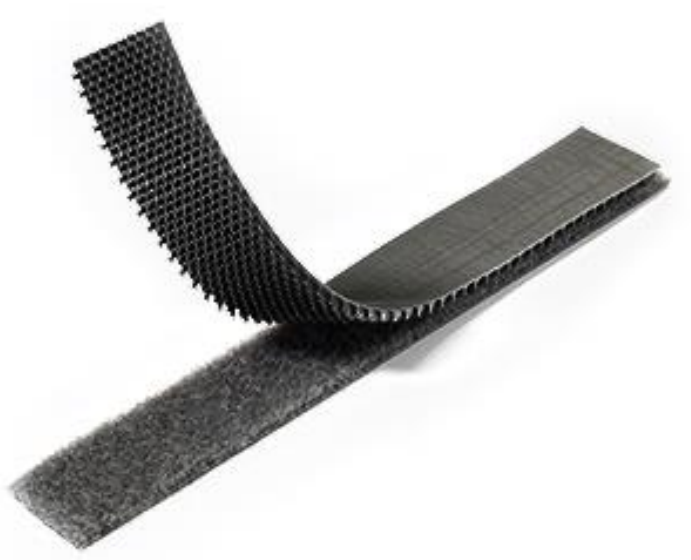

Fonte: www.velcro.com.br/produtos/fixadoresextrafortes/extraforte-extremo\#.WLx8M Pnyu00 (2017).

\subsection{Seleção e redesenho da alternativa final}

A alternativa final foi redesenhada havendo apenas alguns ajustes necessários, a seguir na Figura 07 é apresentado o novo modelo:

Figura 07 - Alternativa final $16^{\circ}$ Ergodesign - Congresso Internacional de Ergonomia e Usabilidade de Interfaces Humano Tecnológica: Produto, Informações Ambientes Construídos e Transporte

$16^{\circ}$ USIHC - Congresso Internacional de Ergonomia e Usabilidade de Interfaces Humano Computador

CINAHPA | 2017 - Congresso Internacional de Ambientes Hipermídia para Aprendizagem.
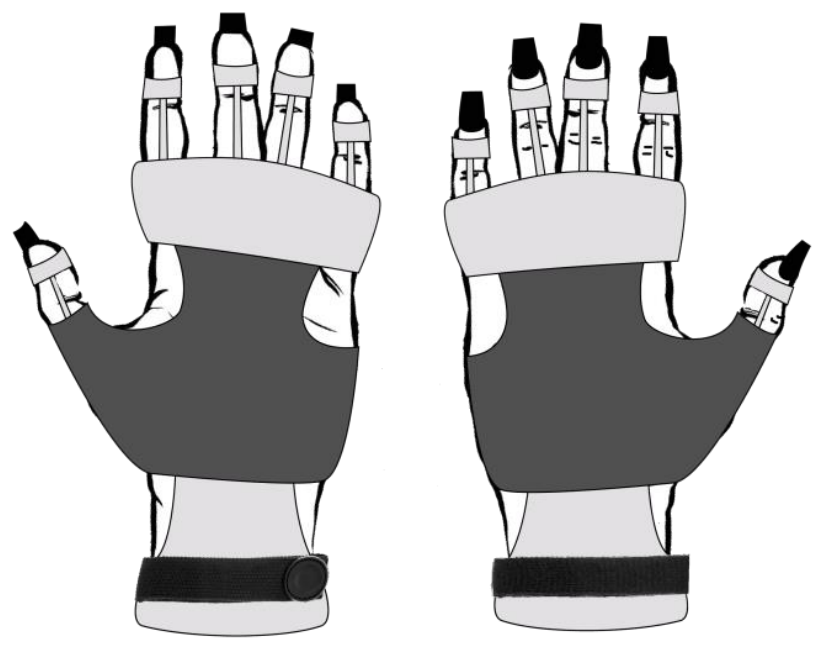

Fonte: Autoria própria

A alternativa final da luva segue com a proposta de utilizar os materiais que foram definidos anteriormente. A luva permite que os componentes eletrônicos possam ser inseridos, mas é preciso fazer um protótipo, para ter resultados reais, ainda podendo haver mudanças após o resultado do protótipo. A luva possui elementos vazados para que a mão possa ficar mais flexível e para que os movimentos se tornem mais livres. Possui também ajustes no pulso, para que possa ser adaptável em diferentes usuários.

\section{Considerações finais}

Para a última etapa do projeto que consiste na execução do protótipo e preparação para a produção é necessário um protótipo em tamanho real da luva, utilizando os materiais escolhidos, bem como a realização de testes para verificar a necessidade de ajustes, para em etapa posterior produzir o produto. Após a realização do protótipo final que se encontra em fase de desenvolvimento, torna-se necessário ainda analisar se os dispositivos eletrônicos desenvolvidos são eficazes e se o formato da luva permite acoplar todos os pontos que são imprescindíveis para o funcionamento da mesma. Por fim, realizar análise de sua possível 


\section{$16^{\circ}$ \\ ERGODESIGN USIHC CINAHPA}

comercialização. Até a etapa conceitual de desenvolvimento do produto, os objetivos foram atingidos com êxito.

Após o término do intercâmbio e o retorno para o Brasil, a luva foi finalizada até a etapa presente e encontra-se ainda em fase de desenvolvimento por outros estudantes da área de Eletrônica e Design, estando sujeito à alterações. A análise ergonômica foi bastante proveitosa, pois a ergonomia exerce uma função bastante relevante nos produtos de design. Além da possibilidade de trabalhar com autores da área e possibilitar uma visão de estudo multidisciplinar. A análise ergonômica deste produto foi importante para o entendimento da funcionalidade da luva e dos diversos usuários que poderão fazer uso do produto, auxiliando no conforto e segurança.

\section{REFERÊNCIAS}

ELECTRONIC PRODUCTS, 2012. [Internet] Disponível em:

<http://www.electronicproducts.com/News/Futu ristic_glove_provides_touch-based_di agnostics.aspx>. Acesso em: 05/11/2016

IIDA, Itiro. Ergonomia: projeto e produção São Paulo: Edgard Blucher, 1990

\section{INSTITUTO POLITÉCNICO DE PORTO,}

2017. [Internet] Disponível em:

<https://portal.ipp.pt/portodesignfactory.aspx>. Acesso em: 15/11/2016

LOBACH, Bernd. Design Industrial: bases para a configuração dos produtos industriais. Rio de Janeiro - Edgard Blucher, 2001

PASCHOARELLI, L. P.; MENIN, M.; SILVA, D. C.; CAMPOS, L. F. A.; SILVA, J. C. P. Antropometria da Mão Humana: Influência do Gênero no Design Ergonômico de Instrumentos Manuais. Revista Brasileira de Ergonomia. Volume 5, número 2. Disponível em:

$<$ http://repositorio.unesp.br/bitstream/handle/11 $16^{\circ}$ Ergodesign - Congresso Internacional de Ergonomia e Usabilidade de Interfaces Humano Tecnológica: Produto, Informações Ambientes Construídos e Transporte

$16^{\circ}$ USIHC - Congresso Internacional de Ergonomia e Usabilidade de Interfaces Humano Computador

CINAHPA | 2017 - Congresso Internacional de Ambientes Hipermídia para Aprendizagem.
449/134500/ISSN1519-7859-2010-05-02-0108.pdf?sequence=1>. Acesso em: 27/10/2016.

TECNOLOGÍA DE LOS PLÁSTICOS, 2012. [Internet] Disponível em:

<http://tecnologiadelosplasticos.blogspot.com.br /2012/10/elastano-spandex.html> Acesso em: $19 / 10 / 2016$

\section{ZARIFEH, Paul. NEOPRENE: THE INSIDE}

STORY: Wetsuit information guide, 2012. [Internet] Disponível em:

$<$ http://www.seventhwave.co.nz/site/seventhwav e/files/Neoprene_Inside_Story.pdf $>$. Acesso em: 23/11/2016

\section{Agradecimentos}

A elaboração deste artigo não teria sido possível sem a colaboração, primeiramente do Instituto Federal de Santa Catarina, pela oportunidade de intercâmbio, à Porto Design Factory pelo espaço e aprendizado, à minha orientadora Profa. Dra. Jucelia Giacomini pelo suporte e auxílio no desenvolvimento do projeto e à minha família pelo apoio.
Realização:

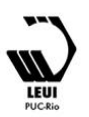

